\title{
The Fusion of College English Flipping Class and Traditional Class
}

\section{--On the Degree of Class-Flipping}

\author{
Weili $\mathrm{Zi}^{1}$ \\ ${ }^{1}$ Foreign Language Department, Beijing Institute of Fashion Technology, Beijing, China \\ Correspondence: Weili Zi, Foreign Language Department, Beijing Institute of Fashion Technology, Beijing \\ 100029, China. Tel: 86-136-2134-2535.
}

Received: November 1, 2016

Accepted: November 21, 2016

Online Published: December 9, 2016

doi:10.20849/aes.v2i1.91

URL: http://dx.doi.org/10.20849/aes.v2i1.91

\begin{abstract}
Flipping Class emphasizes off-line learning with the problems resolved during class to fulfill the internalization. This could promote undergraduates' innovative spirit and critical thinking. However, the essence in traditional teaching should not be ignored. This paper describes the experiment of fusion between traditional class and flipping class with the undergraduates of grade 2014 majoring in fashion and art from BIFT as the case. The action research conducted in this teaching experiment helps us find the great improvement of undergraduates involved in learning habit, learning attitude and English proficiency. Therefore, the author holds that quality teaching for the special learning subjects - undergraduates of fashion and art major could be achieved with the targeted fusion of traditional teaching and flipping teaching in the process of College English teaching. Meanwhile, when carrying out the flipping teaching mode, the characteristics of learning subjects and course taken are supposed to be considered with the moderate degree of flipping to maximize the effect of the new teaching mode.
\end{abstract}

Keywords: flipping class, traditional class, fusion, degree

Flipped classroom sets off a set of teaching reform by subverting the traditional teaching. In flipped classroom, is the traditional teaching mode completely subverted, or combined effectively with the other methods? To what "degree" is the class teaching procedure flipped? The author responds to those questions by much reflection and further thinking after the experiment of flipping class teaching.

\section{Difference between Flipping Class and Traditional Class}

In traditional class, the main task for a teacher is to impart knowledge with the knowledge internalization left after class by completing the corresponding assignments from teachers. The traditional class is not where only the teacher plays "solo", but where the impartment and interaction are effectively combined. Learning is a process of interaction and communication, with the exchange of ideas and transmission of feelings among teachers and students, or just students. Therefore, compared to other teaching modes, the face-to-face interaction and mind-to-mind communication and its learning atmosphere are indispensable and irreplaceable. 


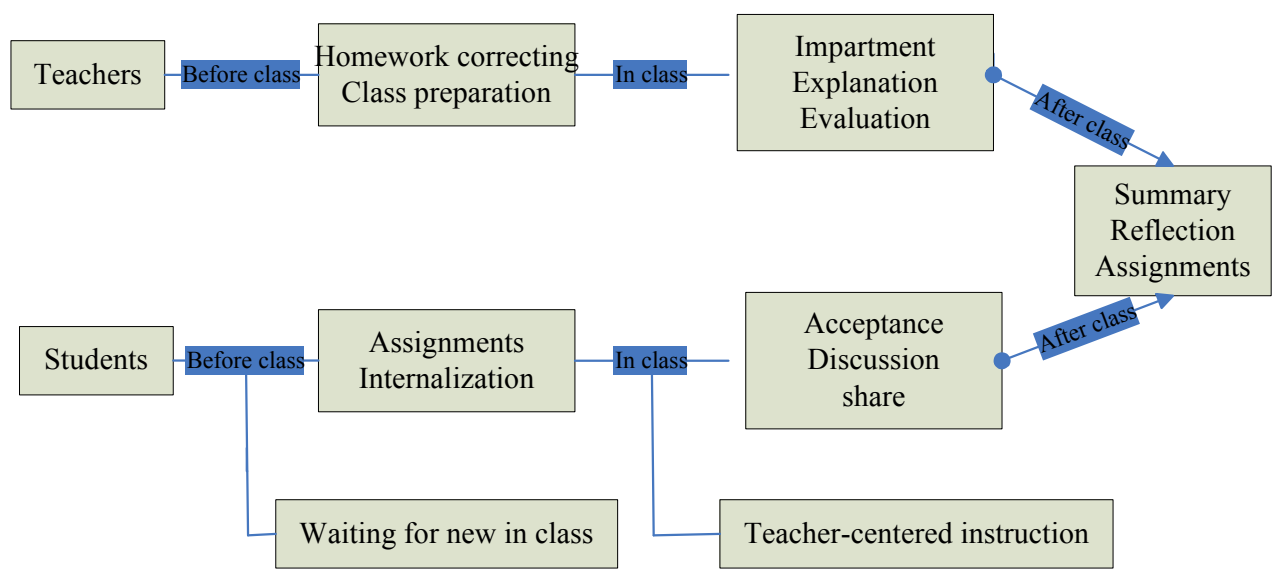

Figure 1. Traditional-class teaching mode

However, with the development of information technology, some of the traditional teaching mode and means are not adaptable to the requirements and goals of modern education. Teacher-centered class cannot meet the needs and interests of each student, nor can it achieve the unity of internalization. So, the traditional teaching mode is required to be reformed to meet the need of both students and education.

Flipping class is a new teaching mode adopted based on online courses, including micro-course online. In the background of big data, the integration of information technology and foreign language courses has obviously been fuel of foreign language teaching and reform, and information technology is playing increasingly helpful role in foreign language teaching. Flipping class has come into being to meet the requirement of technology with student-centered and spontaneous form of learning driven by the individual interest and problem-solving.

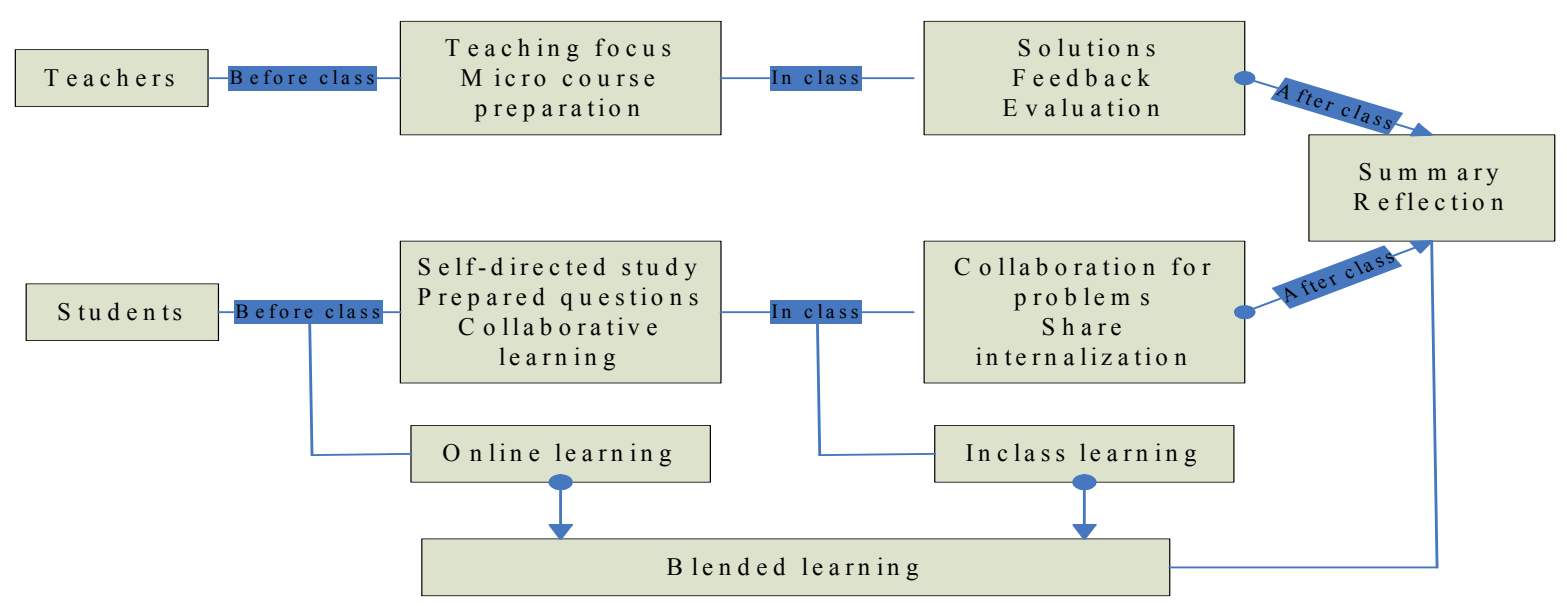

Figure 2. Flipping-class teaching mode

Flipping-class emphasizes the knowledge impartment after class with the aid of visual teaching materials, such as micro-course video, while in class teachers would focus on assistance of internalization, comprehension and application. Obviously, there is well-targeted plan in flipping class by flipping the traditional teaching mode---that is to say, before-class learning is conducted by making good use of information technology---microcourse with the problems solved during class. However, some problems arise while carrying out the flipping class mode, which in reality challenges us, most students prefer to accept knowledge passively instead of putting forward any questions, the learning habit of which dates back to middle school study; some students are reluctant to watch micro-course, just waiting for new in class; some students are inclined to raise questions, but the problem is they don't know how. So, students' failure to watch the micro-courses for the new after class and 
inactivity in putting forward questions during class impels our further thinking: Does flipping class really optimize class teaching with the reversal of teaching and learning procedure or method? What degree should flipping achieve? Can flipping class really meet the personal needs of all students with total emphasis on it? Is traditional class useless? To explore these issues in a more insightful way would facilitate the recognition of each advantage in both classes, and help to achieve the goal of optimizing class teaching with learning from each other and bringing effective fusion of the two.

\section{Literature of Flipping Class Research on Chinese College English during Jan. 2013 and May 2016}

\subsection{The Overall Trend}

According to CNKI database, published articles from all publications in China are collected concerning college English flipping class or flipping class teaching with "flipping class, college English" as the key words, and literature including 416 articles are available as of August 9, 2016. The literature covers articles published from January, 2013 to May, 2016, which of course is less than the real. The overall trend based on CNKI is performed with visualization analysis by Cite Space, a bibliometrics analysis tool, which to some extent, is able to reflect the general picture of College English research on flipping class in China.

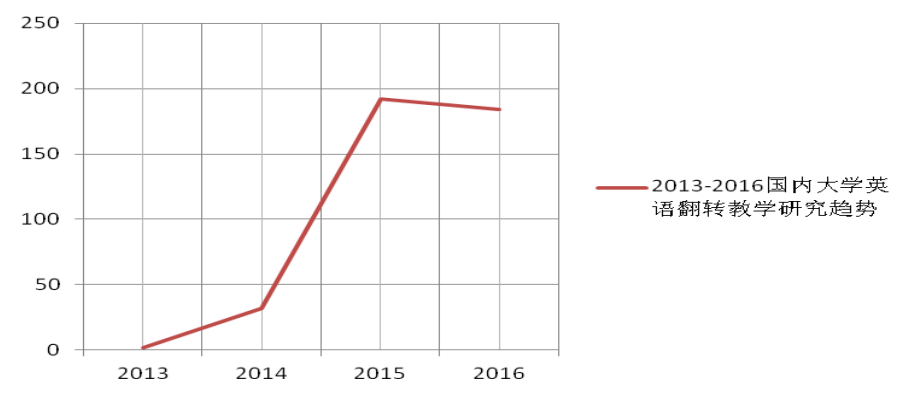

Figure 3. The overall trend of research on college English flipping class in China during Jan. 2013 and May 2016

As Figure 3 shows, researchers begin to discuss this topic since 2013, and the obvious rise of research papers can be seen during 2014 and 2015. As of the day of data collection, the literature only cover those of the first half year in 2016, and the incomplete literature in 2016 leads to decrease in number of research papers in 2016.

\subsection{Research Focus on College English Flipping Class during 2013 and 2016}

Based on the general picture of Chinese flipping class teaching research, we can further study the flipping class teaching with the help of Cite Space, analyzing its present situation, focus and trend, and displaying the related information visually.

Keywords are the highly concentrated and generalized information of the research; its focus in a certain field can be established based on keywords. (Cao Chuandong, Zhao Huaxin, 2016:20-24) Centrality and high frequency keywords indicate what researchers are extremely concerned about over a certain period---that is research hotspot. The higher the co-occurrence frequency of keywords, the closer they are toward centrality, showing the more importance of the node (such as terms, institutes, countries etc.) in the field. As fig. 4 shows among the related literature in China, the higher frequency the keywords are, the closer they are toward the centrality, and the clearer the research hotspot is. Table 1 shows the research focus within the recent three years: flipping class, college English teaching, teaching mode, college English learner, self-directed learning, feasibility, Art College, flipping class teaching mode, college English teacher, blended teaching and individualized teaching, etc. few research shows concern for the combination of flipping class and the traditional. 


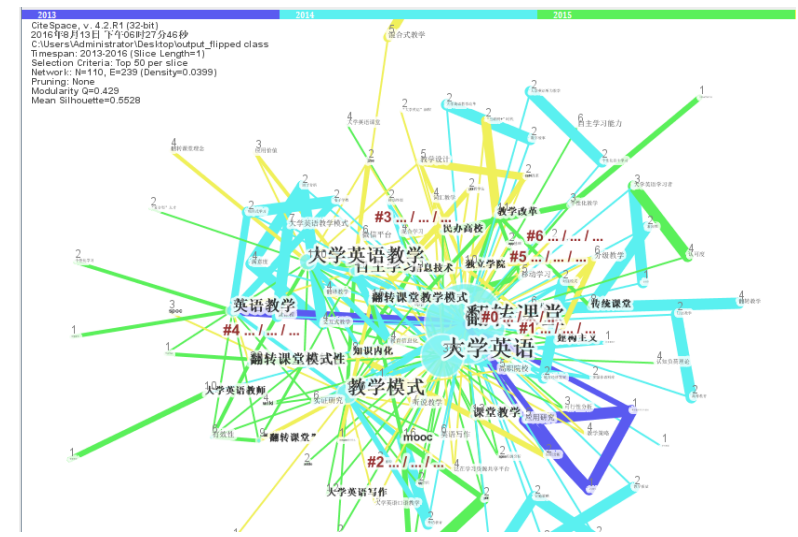

Figure 4. Research focus on college English flipping class teaching in China during 2013.1-2016.5

Table 1. Hot research topic of college English flipping class over the past three years

\begin{tabular}{llllll}
\hline Freq & centrality & sigma & references & year & cluster \# \\
\hline 638 & 1.35 & 1 & Flipping class & 2013 & 0 \\
\hline 356 & 0.37 & 1 & College English & 2014 & 1 \\
\hline 120 & 0.14 & 1 & College English Teaching & 2014 & 3 \\
\hline 116 & 0.14 & 1 & Teaching mode & 2014 & 2 \\
\hline 41 & 0.09 & 1 & Self-directed learning & 2014 & 3 \\
\hline 41 & 0.09 & 1 & English teaching & 2013 & 4 \\
\hline 10 & 0.04 & 1 & College English Teaching & 2014 & 0 \\
\hline 6 & 0.04 & 1 & Art college & 2014 & 3 \\
\hline 5 & 0.04 & 1 & Blended teaching & 2016 & 3 \\
\hline 3 & 0.04 & 1 & Individualized teaching & 2015 & 1 \\
\hline 26 & 0.03 & 1 & feasibility & 2014 & 4 \\
\hline 16 & 0.01 & 1 & mooc & 2014 & 2 \\
\hline 15 & 0.01 & 1 & Flipping class teaching mode & 2015 & 1 \\
\hline
\end{tabular}

From the keywords in Figure 5, we find there are 110 nodes, 239 ligature, global density is 0.0399 , modularity Q is 0.429 , mean silhouette is 0.5528 .

\section{Timezone}

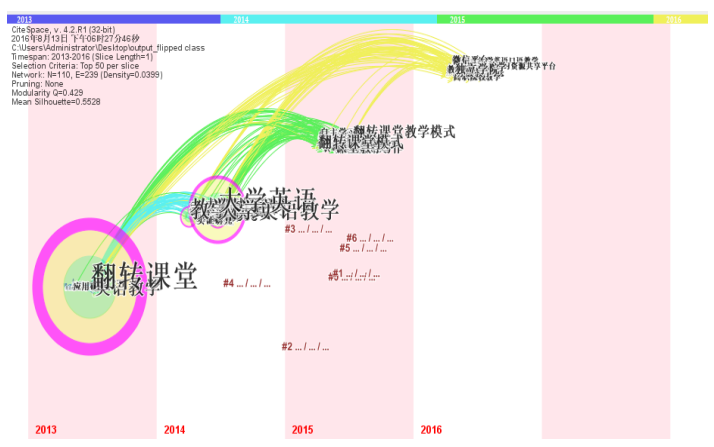

Timeline

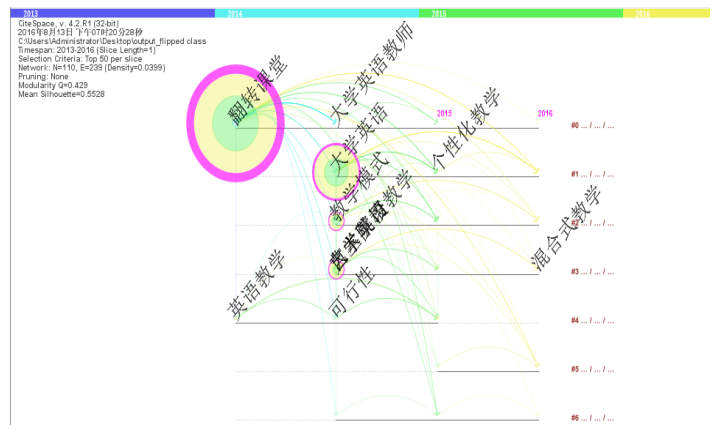

Figure 5. Timeline and Timezone of co-citation literature on flipping class during 2013.1-2016.5 
The research mainly focuses on the following aspects including flipping class, College English teaching, ....(see table 1) the early stage for this research is in 2013, mainly exploring flipping class teaching form; 2014 is the booming stage with abundant research results, mainly focusing on college English teaching, teaching mode, autonomous study, teachers' role and teaching research in art college etc. 2015-2016 belongs to the stage of development, emphasizing individualized learning with students as subjects, and blended teaching etc. College English teaching in China is undergoing teaching reform. With the rise of big data, College English teaching is not only confined to traditional study. It has become a new trend to examine College English teaching mode based on students' needs in terms of internet assistance.

\subsection{Conclusion and Comment}

The timeline view is shown in Fig. 6: research on College English flipping teaching is of great importance in China. The early research dates back to 2013, but springs up in 2014-2015. The prediction can be made that it would gain increasingly widespread concern and the research would be in full swing during 2016-2017. Though the overall research in this field is on up-trends, the high-quality research on flipping teaching is obviously insufficient. So, there is the expectation for the commitment of more researchers to this field. According to keywords con-occurrence view, research focus of college English flipping class is class teaching mode. Keywords co-occurrence is comparatively loose with less high node density, therefore, more researchers are needed to keep further and profound exploration in the topic, content and its direction, and heighten its concern in this field. In the meantime, more attention also needs to be drawn to combination of the new and the traditional.

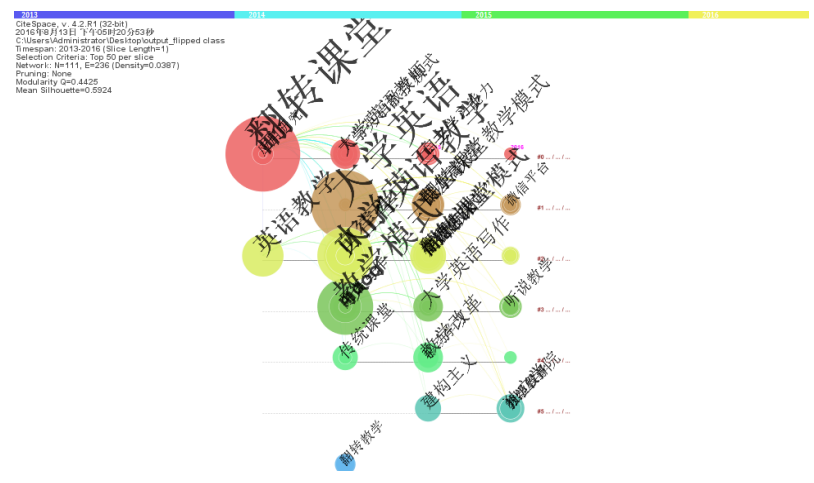

Figure 6. Research trend analysis of the flipping class based on timeline

\section{Effective Fusion of Flipping Class and Traditional Class}

The major difference between flipping class and traditional class lies in the teaching procedure where flipping class follows the first post-teaching with the mode of teaching by learning, overturning the traditional teaching first with learning by teaching. (Ye Bo, 2014:30)

\subsection{Introduction}

An experiment for practicing flipping teaching is conducted in grade 2014 of art design, fashion design, fashion engineering and business major. Art A1 and Fashion engineering A are selected as the experimental classes, while Art A2 and Business A1, Business A2 are the controlled classes. Undergraduates are selected according to College Entrance Examination Achievement in China (CEEAC) and Placement Test (PT) in BIFT; they are all in the advanced level--- A level, with the equal score in both the experimental class and the controlled classes. The controlled classes adopt the traditional method in class teaching while the flipping method is combined with some of the traditional methods in the experimental class. The experiment lasts one year. The purpose for this experiment is to combine the flipping teaching and traditional teaching mode in College English class, observing the effective result of the teaching practice.

\subsection{Research Method}

\subsubsection{The Research Questions}

The questions for this research are as the follows:

(1) Does flipping class really optimize class teaching with the reversal of teaching and learning procedure or 
method? (2) Can flipping class really meet the personal needs of all students with total emphasis on it?

(3) What degree should flipping achieve?

\subsubsection{The Research Subject}

The research subjects are undergraduates majoring in art design, fashion design, fashion engineering and business from grade 2014. Class Art A1 and Fashion engineering A are selected as the experimental classes, while class Art A2 and Business A1, Business A2 are established as the controlled classes. Their English proficiency is on the same level according to CEEAC and PT. There are 62 students in class Art A1 and 55 students in class Fashion engineering A.

All the experimental classes and the controlled classes follow the same English teaching syllabus with the same text books and course schedule except teaching methods.

\subsubsection{The Research Data}

While in experiment, we observe the class effects during class, and after the experiment, their National College English Band 4 Test scores are collected. (National College English Test Band 4, shortened for CET-4, is a large-scale examination for Undergraduates in China). Besides, questionnaires are conducted among some students from both the experimental classes and the controlled classes for their comments on the new teaching method.

\subsubsection{The Research Process}

During Sept. 2014 and July 2015, we conduct an experiment of college English flipping teaching in Art design A1 and Fashion engineering A of grade 2014. Students majoring in art design and fashion engineering are quite different from those in other majors, such as those from business or engineering department majoring in other than fashion. According to College Entrance Examination Achievement, art and fashion students as a whole are weaker in English proficiency, and they are less active in self-directed learning, believing English is less important than their professional knowledge; therefore, teachers' instruction is of great importance. In the first semester, we start the experiment with encouragement of raising questions in the experimental classes: Art A1 and Fashion engineering A. New assignments are arranged before class, it turns out that only several students put forward the problems in class because some fail to prepare the new beforehand, and some believe what is to be learnt is too simple or too difficult to prepare before hand, and still there are some students who don't know how to put forward questions although they have lot questions. In the end of the semester, the experiment is not as what we expect. The unsuccessful experiment challenges us and at the same time encourages us to figure out the way out: proper assignment before hand, moderation in difficulty of assignment, and the way to put forward the questions.

In the second semester, the measure requiring that the activities of raising questions be involved in formative assessment forces those always reluctant to put forward questions to be involved in class interaction. It turns out to be a successful practice. Most students in experimental classes actively engage themselves in various interactions and raise the questions concerning the grammar, translation, even the culture in the text. Surprisingly, some questions from them are really profound. When learning unit 7, book 4 of NHCE (New Concept College English) "Bill Gates", some students are doubtful: why is the receptionist of Bill Gates is the busiest person in the world? Why is Bill Gates always reluctant to travel? Why does he not like to spend money? etc. and all those questions are dealt with during class through discussion guided by teacher. Apparently, students care more for the culture in the text than before.

According to the observation in class: Facing the different learning subjects, the effective fusion of flipping class and traditional class may optimize teaching effect to the great extent based on the individual needs.

\section{1) Self-directed study after-class}

Flipping class is assisted by micro-courses. Online multi-modal video courses are designed exclusively over learning style of art and fashion students. The micro-courses cover two categories---the culture and the language skills. Culture includes western and eastern culture, while language skills covers techniques of writing, reading, translating and etc. the micro-courses are designed by knowledge point, each lasts 5 minutes or so with the questions at the end of each micro-course for further thinking, in the next class, it would be explained in detail by teachers. While in class, besides answering all the questions, teacher would assign the targeted work to them to strengthen what have been discussed, and enlarge their knowledge at the same time. Recording the key and basic enables those students to learn and review according to their own pace, (Nilson, 2013) which is gradually accepted and recognized by them. This teaching mode provides art and fashion students with more freedom for 
autonomous learning despite their limited learning time after class. Over those with different English proficiency, diverse sources of the same topic are provided to satisfy the individual's needs, avoiding absence of learning motivation due to difficulty of learning materials.

\section{2) Flipping teaching in class}

Nowadays, there is a fundamental difference between online interaction and class interaction, although online class cannot totally replace the traditional class. Interaction among students and teachers in flipping class is more individualized and less didactic. Therefore, students perform more actively in commitment to acquiring and constructing knowledge while involving in the learning and assessing. (Alvarez, 2011) Face-to-face interaction in traditional class can optimize the communication effect. Students acquire the critical thinking by thinking, doubting, questioning and evaluating in class with question-answering and knowledge enlarging and commenting from teachers. Face-to-face debating among teachers and students enriches their knowledge and cultivates their critical thinking mind. So, the combination of online learning and face-to-face learning, which is known as blended learning, would achieve the best learning effect. (Matsumoto, 2016) This practice solves the problem of limited teaching time for complicated teaching content. According to the researches, flipping teaching has solved the problem that can't be solved in traditional class where the important teaching content can't be covered within the limited time. (Mason et al., 2013)

Of course, when conducting flipping class teaching, the subject feature can't be ignored. Courses concerning language extremely value language exchange, so collaborative learning and discussion in class seem more important than the autonomous exploration after class. Interaction among students and interaction between teachers and students in traditional class tend to make it easier to deepen the cognition to the problem found after class, to enlarge the knowledge and to stimulate internalization as well.

\subsubsection{The Research Result}

After one-year class experiment, a questionnaire is conducted to find out the undergraduates' attitudes toward the method. The questions are as follows:

Do you accept this teaching method?

Do you agree with putting questions before the new is imparted by teachers?

Do you have any suggestions for this teaching practice?

53 valid questionnaires from Fashion engineering A are collected. Most undergraduates think "this practice in learning process---raising question after self-directed study, is essential," and 49 out of 53 accept this way, which occupies $92.5 \%$ of the total. But among them, 41 students also hold that asking questions during class waste their time, which occupies $77.4 \%$. On one hand, the problem for student A might not be the difficult point for student B. On the other hand, some who are poor in English oral expression would spend a little longer time in class explaining their problems, this would occupy much time of the whole class to listen to his or her questions. They suggest collecting problems before class and explaining during class would be more effective and more popular for them. For them, traditional way to some extent is still useful, they still like face-to-face interaction.

\subsection{Result and Discussion}

\subsubsection{Result}

According to the class observation, flipping class does not necessarily optimize class teaching with the reversal of teaching and learning procedure, because undergraduates of different majors respond differently to the approach due to their learning styles and needs. Therefore, teachers in the experimental classes consistently place the teaching subjects on the first place, taking students' learning styles and the individual needs into account during class. They combine the flipping method with some of the traditional teaching ways while in class, instead of blindly following the flipping class ways. Students from experimental classes are more involved and interested in class, they no longer feel shy before the whole class while explaining their problems, and speaking English more fluently. Those from the experimental class are also found to be more interested in watching the micro-lectures before class, actively arguing with teachers over a topic, and more frequently discussing with teachers for immediate solutions to their doubts in learning through WeChat. Some effective ways such as interaction, face-to-face argumentation, etc. in traditional classes are supposed to be remained and even adopted. The fusion of flipping class and traditional class guarantee the effective interaction among teachers and students, which involves more students in active learning.

One-year practice of new teaching method contributes a lot to their English achievement, especially the achievement that those undergraduates have made in National College English Test Band 4 (CET-4). (See table 
2): after the one-year teaching reform, all the experimental classes and the controlled classes take part in the large-scale examination exclusively for college students in China in June 2016. Those from the experimental classes have achieved a better performance than those from the controlled classes. According to Table 2, we find the experimental Art A1 is 6.5 percent higher than the controlled Art A2. The experimental Fashion engineering $\mathrm{A}$ is respectively 7.6 percent and 5.4 percent higher than the controlled Business A1 and Business A2, which obviously demonstrates the positive teaching effect by adopting the fusion of flipping class and traditional class.

Table 2. Comparison of CET- 4 between the experimental class and the controlled class

\begin{tabular}{|c|c|c|c|c|}
\hline Type of class & The experin & controlled class & The passing rate & Note \\
\hline \multirow{2}{*}{$\begin{array}{l}\text { Art and } \\
\text { Fashion }\end{array}$} & experimental & Class Art A1 & 81.5 & \multirow{2}{*}{$\begin{array}{l}\text { Compared with the } \\
\text { controlled Class Art A2, the } \\
\text { experimental class Art A1 is }\end{array}$} \\
\hline & controlled & Class Art A2 & $74 \%$ & \\
\hline \multirow{3}{*}{$\begin{array}{c}\text { Fashion } \\
\text { Engineering } \\
\text { and Business }\end{array}$} & experimental & $\begin{array}{c}\text { Class Fashion } \\
\text { Engineer A }\end{array}$ & $88 \%$ & \multirow{3}{*}{$\begin{array}{l}\text { experimental Fashion } \\
\text { engineering A is respectively } \\
7.6 \text { and } 5.4 \text { percent higher } \\
\text { than the controlled class } \\
\text { Business A1 and class } \\
\text { Business A2. }\end{array}$} \\
\hline & controlled 1 & Class Business A1 & $80.4 \%$ & \\
\hline & controlled 2 & Class Business A2 & $82.4 \%$ & \\
\hline
\end{tabular}

The fusion of both flipping class and traditional class has yielded much benefit, but when referring to the flipping class teaching, "Degree" of flipping draws our attention for further thinking.

\subsubsection{Discussion of Degree of Flipping Class Teaching}

Flipping teaching has made great changes in teacher's role, student's role, teachings process, teaching content, technology application and evaluation mode, marking the transformation of following requirements of social development and the direction of educational development as well. However, every kind of teaching mode is a powerful yet fragile tool. (Bruce, 2002) Teaching effect cannot be greatly improved by fastidiously copying flipping class known as a new teaching mode. The extent to class-flipping during teaching is supposed to be concerned. As we all know, flipping-class mode is indeed of great value in heightening acquisition ability, autonomous learning ability, problem-solving ability, but it has its own limitations in terms of the role played by teaching in students' all-round development, emotion, attitudes, sense of value and their view on meaning of life. (Ye Bo, 2014) The adoption of new teaching mode varies with each individual. For example, over Art and Fashion major students, the desired effect cannot be achieved by totally copying flipping-class mode. Because those students are a little bit poorer in terms of autonomous learning after class, and less rigorous in attitude towards English study compared to those majoring in engineering or business. Lack of self-management skills and self-instruct often leads to their reluctance to watch the new knowledge online again and again. Heavy specialized course loads shrink them back from any difficulty, and leave limited time for thinking the new. In this case, teachers' instruction in class becomes extremely important, where the emotional exchange between teachers and students and the face-to-face exchange of reflection on value and meaning of life would stimulate their enthusiasm for learning. According to class observation, in-class explanation and collaborative learning activity proves to be more active and effective in learning. Conversely, blindly highlighting the pattern of in-class question answering and after-class autonomous study but ignoring the feature of the learning subjects and learning contents would turn only out to be twice the work with half the results.

Indeed, some knowledge in college English are needed to impart to students in class. However, what content and which knowledge points are suitable for flipping class? Should all knowledge be acquired in research-based learning way? Are all content good for out-of-class study online with in-class question answering? So, we need to have the in-depth study on students' situation, characteristics of learning subjects and course requirement, etc.

Therefore, when conducting flipping class teaching, both diverse characteristics of learning subjects and fusion of the traditional teaching and the new should be taken into account to explore the best and the most proper teaching mode under big data and information technology, which is quiet good for learning subjects.

\section{Conclusion}

Ten-year Development Plan of Education Informatization [2010-2020] in China points out, education develops 
with innovative education idea as the orientation, with quality education resources and informationized learning environment construction as basis, with the learning style and innovative education mode as the core. The development of education informatization is supposed to be original idea-led with the quality education resources and learning environment of informatization as the basis, and with the learning way and innovative education mode as the core, with which flipping teaching is just consistent. The advantages of the flipping class lie in highlighting blending mode by online and offline learning, forming a new teacher-student relationship, and promoting the effective usage of resources. However, while in flipping class, be sure to take the characteristics of learning subjects into account, exploring the right fusion of traditional method and the new. It is obvious that the moderation of flipping in teaching would definitely maximize the learning effect. Above all, just like what Bergmann \& Sams emphasize: There is the inadequacy in new teaching method, but the improvement and perfection would be continually achieved in the process of practicing it. (Bergmann \& Sams, 2012)

\section{Acknowledgements}

The paper is sponsored by both the project of Reform and Innovation Team of College English Teaching in BIFT (JGTD-1406) and the project of Research on College English Teaching Mode Based on Micro-lectures $(J G-1521)$.

\section{References}

Alvarez, B. (2011). Flipping the Classroom: Homework in Class, Lessons at Home. Education Digest: Essential Readings Condensed For Quick Review, 77, 18-21.

Bergmann, J., \& Sams, A. (2012). Flip Your Classroom: Reach Every Student in Every Class Every Day. Washington DC: International Society for Technology in Education, 120-190.

Bruce Joyce. (2002). Teaching Model, translated by Jing Jian, et al.. Beijing: China Light Industry Press, 25.

Cao, C., \& Zhao, H. (2016). On Mapping Knowledge of Blending Learning during 2005-2014. Heilongjiang Researches on Higher Education, (5), 20-24.

Education Ministry. (2016-9-18). Ten-year Development Plan of Education Informatization (2010-2020). Retrieved from http://www.moe.edu.cn/publicfiles/business/htmlfiles/moe/moe_838/201008/93704.html

Kristen, M., \& Amy, M. (2015). The Flipped Classroom in Counselor Education. Counselor Education \& Supervision, (54), 32-43.

Mason, G. S., Shuman, T. R., \& Cook, K. E. (2013). Comparing the effectiveness of an inverted classroom to a traditional classroom in an upper-division engineering course. IEEE Transactions on Education, (56), 430-435.

Matsumoto, T. (2016). The Flipped Classroom Experience of Gamified. Creative Education, 7, 1475-1479. http://dx.doi.org/10.4236/ce.2016.710152.

Ye, B. (2014) What has flipped in flipping class-On the value and degree of flipping class. Course-Teaching Materials·Teaching Method, (10), 30-32.

\section{Copyrights}

Copyright for this article is retained by the author(s), with first publication rights granted to the journal.

This is an open-access article distributed under the terms and conditions of the Creative Commons Attribution license (http://creativecommons.org/licenses/by/4.0/). 